\title{
ДИВЕРСИФИКАЦИЯ В МЕХАНИЗМЕ ПОВЫШЕНИЯ ЭФФЕКТИВНОСТИ ПОРТОВЫХ УСЛУГ
}

\author{
(c) 2020 Дроздова Екатерина Сергеевна \\ преподаватель \\ Университет экономики и управления, Россия, Симферополь \\ E-mail: ekadrzdva@gmail.com
}

В социально-экономической жизни общества важное место занимает эффективность функционирования морских портов, одним из перспективных вариантов достижения которой является проведение диверсификации портовых услуг. В аспекте совершенствования организационноэкономических отношений, возникающих в процессе диверсификации услуг, осуществлена разработка методов оценки степени диверсификации портовых услуг, нашедших отображение в ряде формул, позволяющих выявить резервы роста эффективности услуг портовых предприятий. Определена немаловажная роль инструментария маркетинга для их задействования и оптимизации.

Ключевые слова: портовые услуги, эффективность, диверсификация, морские порты, степень диверсификации, резервы диверсификации, маркетинг.

Морские порты на каждом этапе экономического развития страны играют значительную роль в социально-экономической жизни общества. Современный морской порт уже является не просто пунктом для грузоперевалки и обработки разных видов транспорта, он существенно расширяет сферу своей деятельности, превращаясь в центр распределения и переработки грузов с оказанием широкого спектра сопутствующих услуг. Кроме того, морской порт занимает определенное место в логистической цепочке, и, соответственно, для сохранения прибыльности всей задействованной системы, предоставляемые портом услуги должны соответствовать запросам настоящих и потенциальных клиентов.

Однако в настоящее время недостатки процессов социально-экономического развития, которые являются первопричиной современных проблемных ситуаций, включая снижение эффективности управления [1], приводят к низкой результативности оказания услуг морских портов. Помимо этого, с развитием рынка и появлением новых предприятий-конкурентов одновременно возрастает риск невостребованности имеющихся портовых работ/услуг, нейтрализовать который возможно посредством преобразования определенных видов портовых услуг, тем самым диверсифицировав их и повысив первоначальную рентабельность.

Для того чтобы четко представить вероятные причины и механизмы различий в результатив- ности функционирования морских портов при имеющихся сходных инфраструктурах и предоставляемых портовых услугах, следует точнее разобраться в первопричинах сложившегося положения, одним из основополагающих элементов которого является эффективность. Следует отметить, что эффективность, которая всегда находится в связке с практикой, одновременно является как стимулом, так и своеобразным индикатором развития. Проблемам разработки теории и повышения эффективности существенное внимание уделяли такие российские и зарубежные исследователи, как АсаулА.Н., Лозовский Л.Ш., Примачев Н.Т., РайзбергБ.А., Стародубцева Е.Б, Томилов В.В.

С целью повышения эффективности услуг морского порта первоначально определяют необходимые меры, содействующие совершенствованию (например, диверсификация портовых услуг), и отбирают те, которые будут способны обеспечить развитие. Для оценки эффективности предприятия транспортного комплекса, как и для любой экономической структуры, все более частое использование приобретают результаты хозяйственной деятельности, выступающие в роли основных показателей: чистая текущая стоимость; чистый доход организации в целом/ чистый доход за осуществление определенной деятельности [4]; размеры понесенных расходов; период восстановления использованных ресурсов; сроки реализации 
главной производственной задачи. Кроме того, для проведения оценивания эффективности реализуемых услуг непосредственно морского порта применяются экономические и эксплуатационные показатели, в свою очередь по принятой дифференциации подразделяющиеся на качественные и количественные [2, с. 79].

Соответственно, в настоящее время все большей популярностью пользуются частные показатели эффективности для характеристики результатов проведенной деятельности. Также следует учитывать состояние и динамику портового развития в целом. Далее, в целях усовершенствования организационно-экономических отношений, возникающих в процессе диверсификации портовых услуг, среди возможных решений предлагается разработка методов оценки степени диверсификации портовых услуг, реализуемых при помощи ряда формул для повышения их эффективности, позволяя выявить среди исследуемых морских портов наиболее эффективно функционирующие и определить позицию интересуемого морского порта по сравнению с данными успешных портовых предприятий (например, текущую позицию морских портов Крыма).

Так, определение степени диверсификации может рассматриваться в качестве инструмента, позволяющего определить для каждого исследуемого морского порта его текущее положение относительно выявленного эталона - максимального количества существующих и предоставляемых в настоящее время портовых услуг (42). В свою очередь, коэффициент диверсификации портовых услуг отображает отношение степени диверсификации морского порта к максимальному количеству реализуемых в настоящее время портовых услуг, при этом максимальное значение коэффициента диверсификации портовых услуг равно единице, что соотносимо с максимальным количеством существующих в настоящее время портовых услуг с учетом количества новых, разработанных в перспективе портовых услуг.

Таким образом, в соответствии с концепцией об опережающем развитии на основе эмпирических данных за 100\% принимаем теоретически возможный уровень диверсификации портовых услуг, а за $80 \%$ - уровень диверсификации максимума существующих в настоящее время портовых услуг. Далее определяем резерв диверсификации роста портовых услуг интересуемого морского порта первоначально относительно $80 \%$, а затем - 100\%. Следовательно, расчет вышеперечисленных показателей позволяет в итоге выявить неиспользованный резерв диверсификации морского порта, его развития, задействование которого позволит увеличить эффективность функционирования морского порта при помощи расширения спектра реализуемых услуг. Представим формулы, позволяющие определить степень диверсификации портовых услуг и неиспользованные резервы диверсификации портовых услуг:

1) Максимальная диверсификация портовых услуг (включает максимальное количество существующих в настоящее время портовых услуг и количество новых, разработанных в перспективе портовых услуг $\left(\mathrm{M}_{\mathrm{ax}} Д_{\text {ив }} \mathrm{Y}\right)$.

$$
\mathrm{M}_{\mathrm{ax}} Д_{\text {ив }} \mathrm{y}=\left(\frac{\mathrm{y}_{\max }}{\mathrm{y}_{\mathrm{p}} Д_{\text {ив }} \mathrm{y}}\right) * \mathrm{M}_{\text {ах }} \mathrm{y}_{\text {р }} Д_{\text {ив }} \mathrm{y}
$$

где $\mathrm{y}_{\max }-$ максимальное количество существующих и предоставляемых в настоящее время портовых услуг в реальных морских портах (42 услуги, в соответствие с таблицей 1); $\mathrm{y}_{\mathrm{p}} Д_{\text {ив }} \mathrm{Y}$ - уровень диверсификации наибольшего количества (максимума) существующих портовых услуг, принимаем за $80 \%$; $\mathrm{M}_{\mathrm{ax}} \mathrm{У}_{\mathrm{p}} Д_{и в} \mathrm{У}$ - максимальный уровень диверсификации портовых услуг (включает уровень диверсификации максимума существующих в настоящее время портовых услуг в размере $80 \%$ и 20\% перспективного развития сектора портовых услуг), принимаем за $100 \%$.

$$
\mathrm{M}_{\text {ах }} Д_{\text {ив }} \mathrm{y}=\left(\frac{42}{80}\right) * 100=52,5=53
$$

Соответственно, для всех исследуемых морских портов максимальная диверсификация портовых услуг составляет 53 услуги.

2) Степень диверсификации портовых услуг (определенного морского порта), \% ( $\left.\mathrm{C}_{\text {див }}\right)$.

$$
\mathrm{C}_{\text {див }}=\frac{\left(\mathrm{M}_{\mathrm{ax}} \mathrm{y}_{\mathrm{p}} Д_{\text {ив }} \mathrm{y} * \mathrm{y}_{\text {мп }}\right.}{\mathrm{M}_{\text {ах }} Д_{\text {ив }} \mathrm{y}}
$$

Можно представить окончательный вариант формулы:

$$
\begin{gathered}
\mathrm{C}_{\text {див }}=\frac{\left(\mathrm{M}_{\mathrm{ax}} \mathrm{y}_{\mathrm{p}} Д_{\text {ив }} \mathrm{y} * \mathrm{y}_{\text {мП })}\right.}{\left(\frac{\mathrm{y}_{\max }}{\mathrm{y}_{\mathrm{p}} Д_{\text {ив }} \mathrm{y}}\right) * \mathrm{M}_{\mathrm{ax}} \mathrm{y}_{\mathrm{p}} Д_{\text {ив }} \mathrm{y}}= \\
=\frac{\mathrm{y}_{\mathrm{M \Pi}}}{\left(\frac{\mathrm{y}_{\max }}{\mathrm{y}_{\mathrm{p}} Д_{\text {ив }} \mathrm{y}}\right)}=\frac{\mathrm{y}_{\mathrm{M \Pi}} * \mathrm{y}_{\mathrm{p}} Д_{\text {ив }} \mathrm{y}}{\mathrm{y}_{\max }}
\end{gathered}
$$


где $\mathrm{У}_{\mathrm{MП}}-$ количество портовых услуг, предоставляемых в настоящее время морским портом;

3) Неиспользованный резерв диверсификации от уровня диверсификации максимума существующих на сегодняшний день портовых услуг,\% $\left(\mathrm{P}_{\mathrm{H}}\right)$.

$$
\mathrm{P}_{\mathrm{H}}=\mathrm{y}_{\mathrm{p}} Д_{\text {ив }} \mathrm{Y}-\mathrm{C}_{\text {див }}
$$

4) Суммарный неиспользованный резерв диверсификации от уровня диверсификации максимума существующих в настоящее время портовых услуг $80 \%$ и 20\% перспективного развития сектора портовых услуг, \% $\left(\mathrm{CP}_{\mathrm{H}}\right)$.

$$
\text { С } \mathrm{P}_{\mathrm{H}}=\mathrm{M}_{\mathrm{ax}} \mathrm{y}_{\mathrm{p}} \text { иив }_{\text {ив }} \mathrm{y}-\mathrm{C}_{\text {див }}
$$

5) Коэффициент диверсификации портовых услуг (на максимальный уровень диверсификации существующих в настоящее время портовых услуг $80 \%),\left(\mathrm{K}_{\text {див }} \mathrm{C}\right)$.

$$
\kappa_{\text {див }} \mathrm{C}=\frac{\mathrm{C}_{\text {див }}}{\mathrm{y}_{\text {р } Д_{\text {ив }} \mathrm{y}}}
$$

6) Коэффициент диверсификации портовых услуг (на максимальный уровень диверсификации существующих в настоящее время портовых услуг $80 \%$ и $20 \%$ перспективного развития сектора портовых услуг), ( $\left.\mathrm{K}_{\text {див }} \mathrm{M}_{\mathrm{ax}}\right)$.

$$
\kappa_{\text {див }} \mathrm{M}_{\mathrm{ax}}=\frac{\mathrm{C}_{\text {див }}}{\mathrm{M}_{\mathrm{ax}} \mathrm{y}_{\mathrm{p}} Д_{\text {ив }} \mathrm{y}}
$$

Таким образом, осуществив расчеты с использованием формул (1-6) и данных о предоставляемых услугах исследуемых морских портов, получаем данные о степени и доле диверсификации реализуемых портовых услуг исследуемых морских портов России и мира (таблица 1), на основании которых можно сделать следующие выводы:

1. Наилучшие показатели демонстрируют порты Роттердам и Антверпен, количество оказываемых услуг которых отображает максимальное количество существующих в настоящее время портовых услуг среди исследуемых морских портов, соответственно, значение коэффициента диверсификации портовых услуг, существующих в настоящее время равно 1; в свою очередь, степень диверсификации данных портов-эталонов от максимума существующих портовых услуг равна $80 \%$, а коэффициент диверсификации портовых услуг, учитывающий перспективы развития сектора портовых услуг равен 0,80 ; при этом неиспользованный резерв диверсификации от максимума существующих портовых услуг равен 0, поскольку порты Роттердам и Антверпен максимально диверсифицировали диапазон предлагаемых услуг, а суммарный неиспользованный резерв диверсификации (при учете развития сектора портовых услуг) составляет $20 \%$.

2. Среди российских исследуемых морских портов наиболее высокие результаты получил Новороссийский морской торговый порт: степень диверсификации его услуг составила 72,38\%, коэффициент диверсификации портовых услуг, существующих в настоящее время и коэффициент диверсификации портовых услуг, учитывающий развитие сектора портовых услуг составили 0,90 и 0,72 соответственно, а неиспользованный резерв диверсификации от максимума существующих портовых услуг достиг всего 7,62\% (при суммарном неиспользованном резерве диверсификации 27,62\%). Кроме того, Находкинский морской рыбный порт и Владивостокский морской порт также обладают сравнительно высокими значениями показателей: степенью диверсификации портовых услуг в $66,67 \%$ и 53,33\% и, соответственно, коэффициентами диверсификации портовых услуг в размере более 0,53 .

3. Что касается показателей ГУП «Крымские морские порты», следует отметить, что степень диверсификации его услуг достигла всего 38,10\% (против 80\% эталонов), коэффициент диверсификации портовых услуг, существующих в настоящее время и коэффициент диверсификации портовых услуг, учитывающий развитие сектора портовых услуг составляют 0,48 и 0,38 соответственно. При этом у данного предприятия достаточно большой нереализованный потенциал: неиспользованный резерв диверсификации от максимума существующих портовых услуг $41,90 \%$, а суммарный неиспользованный резерв диверсификации -61,90\%.

Также в целях управления эффективностью и диверсификацией услуг морских портов, несомненно, важным является решение одной из основных проблем рыночной экономики: проблемы реализации продукции/услуг, которое может быть получено посредством задействования 


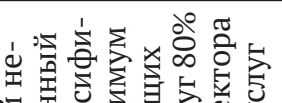

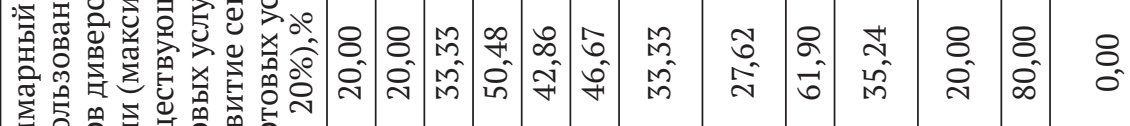

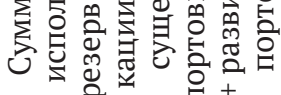

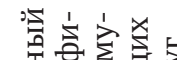

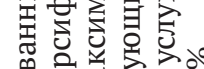

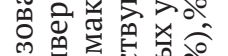

空它岕

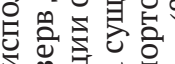

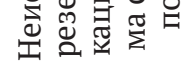

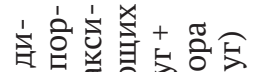

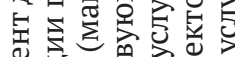

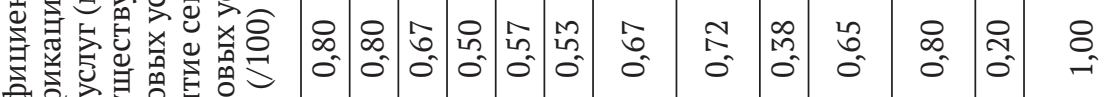

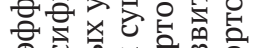

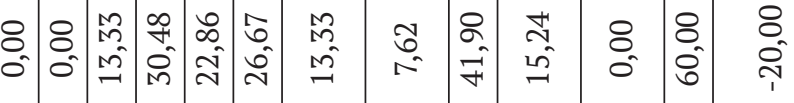

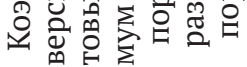

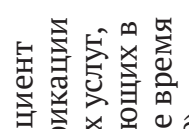

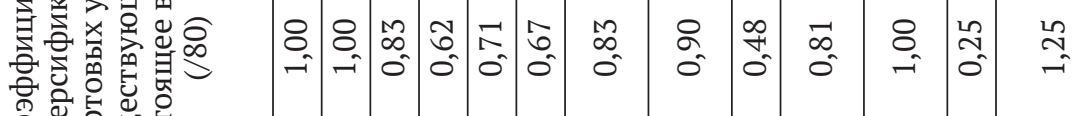

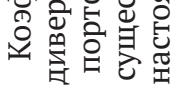

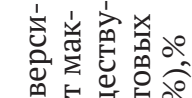

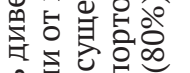

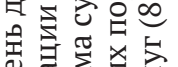

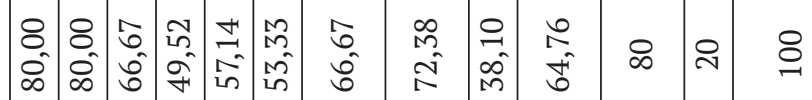

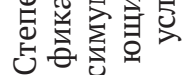

递

窟

近范

营范

年

惫

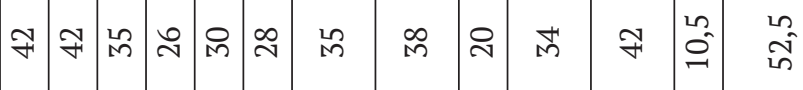
곤

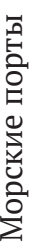

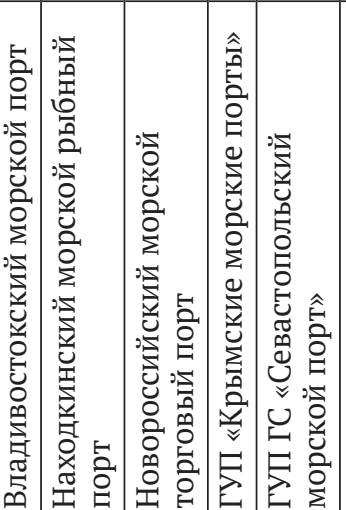


возможностей электронной коммерции и маркетинга в совокупности. При этом маркетинг ориентирован не только на определение нереализованного спроса как такового, а, в первую очередь, на выявление удовлетворенности спроса в последующих периодах, что имеет большое значение для эффективного функционирования морских портов, поскольку их конечным продуктом деятельности являются определенные работы/услуги, одним из свойств которых является невозможность создания запаса. Соответственно, маркетинг предоставляет возможности своевременного корректирования выбранного вектора развития портового предприятия, используя как традиционные маркетинговые инструменты, так и современные интернеттехнологии [3]. Учитывая данные особенности, маркетинг позволяет: сформировать определенную ценовую политику (ставки тарифов и др.) на рынке портовых услуг, способы осуществления взаимодействия морского порта с потребителями; обеспечить проведение рекламной активности; наработать положительный имидж морско- го порта [5].

Таким образом, в современных рыночных условиях эффективность является одним из ключевых факторов успешного функционирования портовых предприятий, перспективным вариантом достижения которой является диверсификация портовых услуг. При этом представленные методы оценки степени диверсификации портовых услуг способствуют проведению оптимизации организационно-экономических отношений, возникающих в процессе диверсификации портовых услуг, позволяя оценить текущий уровень диверсификации морского порта и предпринять соответствующие меры по задействованию его имеющихся резервов диверсификации. В свою очередь, установлена актуальность осуществления маркетинговых исследований, позволяющих организовать деятельность портового предприятия на основании детального изучения тенденций рынка и его существующих потребностей в портовых услугах для получения стабильных значительных финансовых результатов.

\section{Библиографический список}

1. Алехин, Э.В. Исследование социально-экономических и социально-политических процессов: учебное пособие [Электронный ресурс] / Э. В.Алехин; Пензенский государственный университет.-Пенза: ПГУ, 2008.$160 \mathrm{c.}$

2. Винников, В.В. Экономика предприятия морского транспорта (экономика морских перевозок): учебник для вузов водного транспорта / В. В. Винников. - 2-е изд., перераб. и доп.- Одесса: Латстар, 2001. - 416 с.

3. Гаспариан, М.С. Применение информационных технологий в экономике и управлении / М.С. Гаспариан, Г.Н. Лихачева, Е. Г. Хрусталев, В.П.Божко.- М.: МЭСИ, 2002.-47 с.

4. Николаева, Н.К. Об оценке эффективности работы морских портов / Н.К.Николаева, А.Л.Давыдова // Фундаментальные исследования.-2004.- № 3.- С. 147-148.- Режим доступа: http://www.fundamentalresearch.ru/ru/article/view?id=4975 (дата обращения: 20.04.2020 г.).

5. Спивак, В.А. Современные бизнес-коммуникации / В.А. Спивак.-СПб.: Питер, 2002. - 448 с.

6. United Nations Conference on Trade and Development [Электронный ресурс]: сайт.- Режим доступа: https:// unctad.org/en/Pages/Home.aspx (дата обращения: 22.03.2020 г.). 